\title{
Plugged In: How Americans Charge Their Electric Vehicles
}

Findings from the largest plug-in electric vehicle infrastructure demonstration in the world

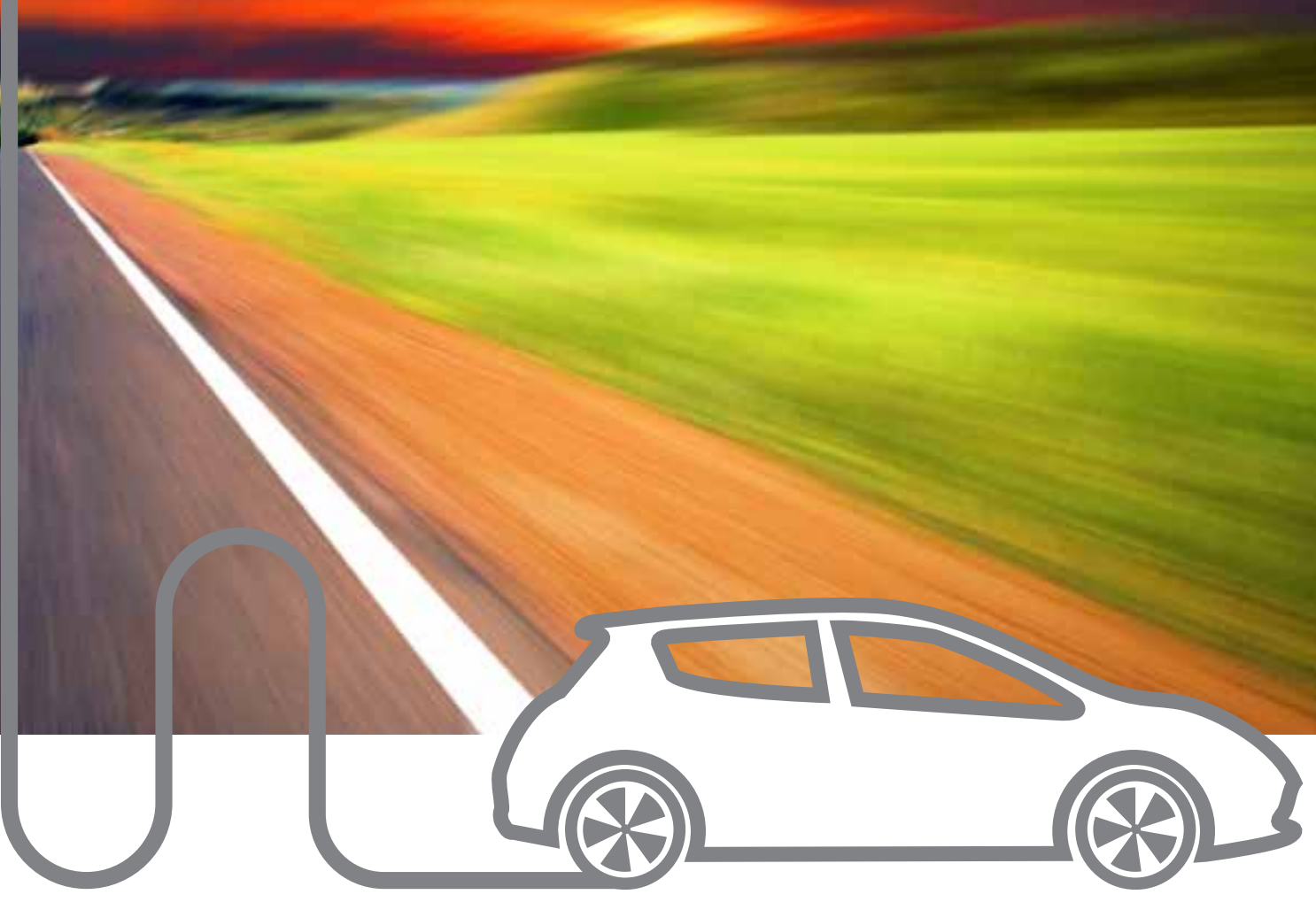

Idaho National Laboratory 


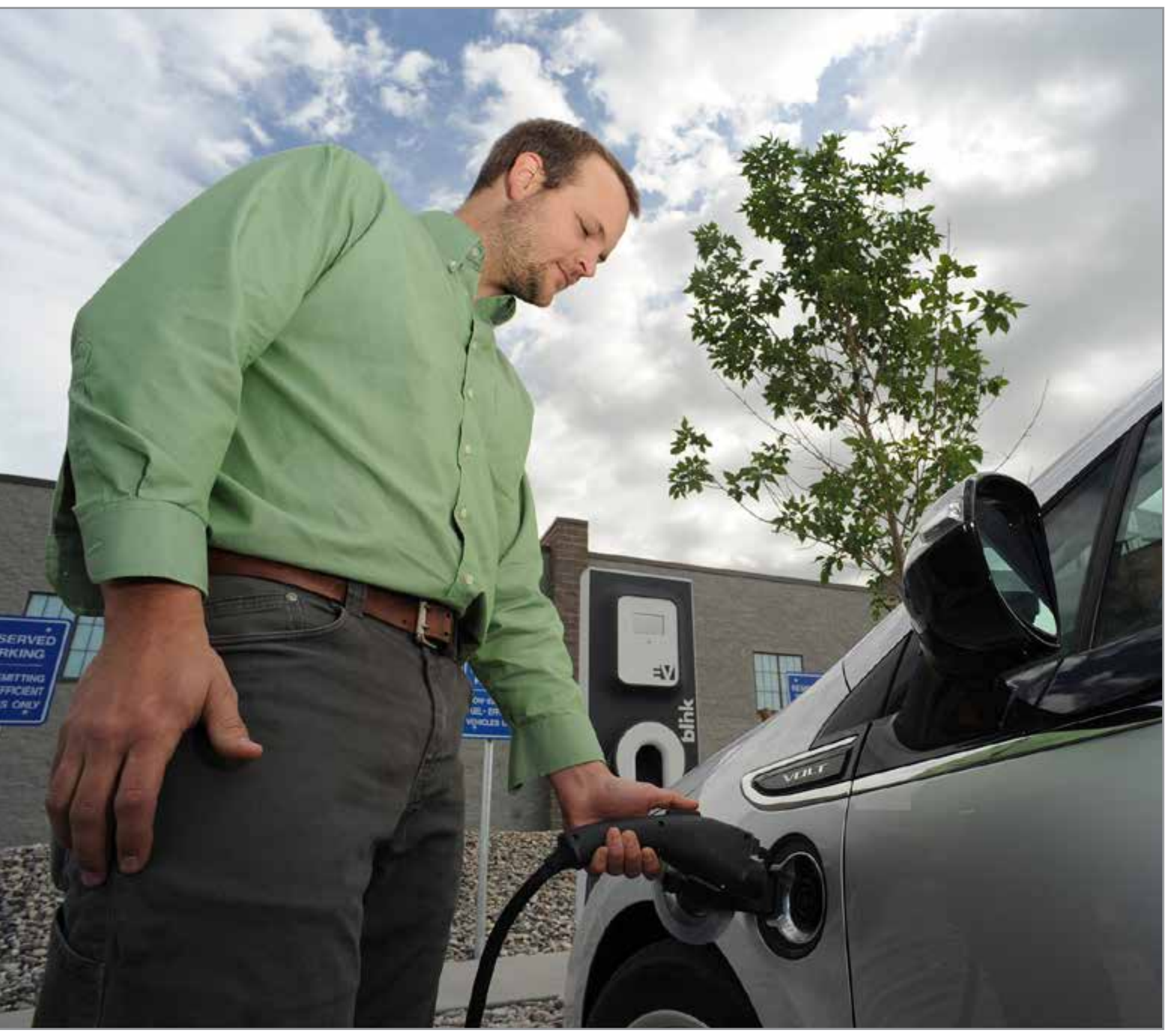




\section{Building the Laboratory}

\section{Widespread adoption of plug-in electric vehicles (PEVs) has the potential to significantly reduce our nation's transportation petroleum consumption and greenhouse gas emissions.}

Barriers to PEV adoption remain, however. One of the most commonly cited barriers is the need for places for PEV drivers to plug in their vehicles. How many and what kind of charging stations are needed? Where and how often do PEV drivers charge?

To answer these questions, the U.S. Department of Energy launched The EV Project and the ChargePoint America project. Combined, these projects form the largest PEV infrastructure demonstration in the world. Between Jan. 1, 2011, and Dec. 31, 2013, this combined project installed nearly 17,000 alternating current (AC) Level 2 charging stations for residential and commercial use and over 100 dual-port direct current (DC) fast chargers in 22 regions across the United States. More than 8,000 privately owned Nissan Leafs and
Chevrolet Volts and more than 300 Smart ForTwo Electric Drive vehicles in Car2Go car-sharing fleets were enrolled in the project.

This project was not just about installing charging infrastructure; the purpose was to build a living laboratory to study its use and learn.

To accomplish this, Idaho National Laboratory partnered with the Blink Network, ChargePoint, General Motors and OnStar, Nissan North America, and Car2Go to collect and analyze data from the electric vehicle charging stations and vehicles enrolled in the project.

Private vehicle owners participating in the project had an AC Level 2 (240-volt) charging unit installed in their residences. In return, they gave written consent for researchers to collect and analyze data from their home charging units and their PEVs. Data also was collected from publicly accessible charging stations installed at a wide variety of venues in and between metropolitan areas around the United States.

Data collected from vehicles and charging infrastructure over the 3-year project period captured almost 125 million miles of driving and 6 million charging events, providing the most comprehensive view of PEV and charging usage to date.

Through partnerships with states, municipalities, electric utilities, local business owners, and numerous other stakeholders, The EV Project and ChargePoint America installed charging stations in 22 regions across the United States, shown in Figure 1.

\section{blink}

-chargepoint
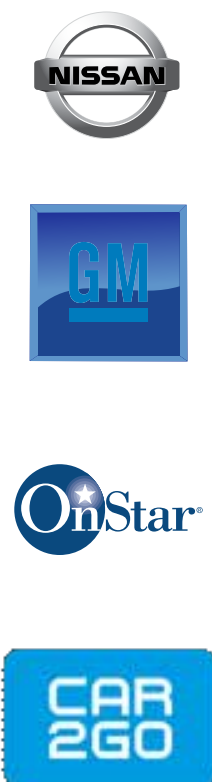
Figure 1.

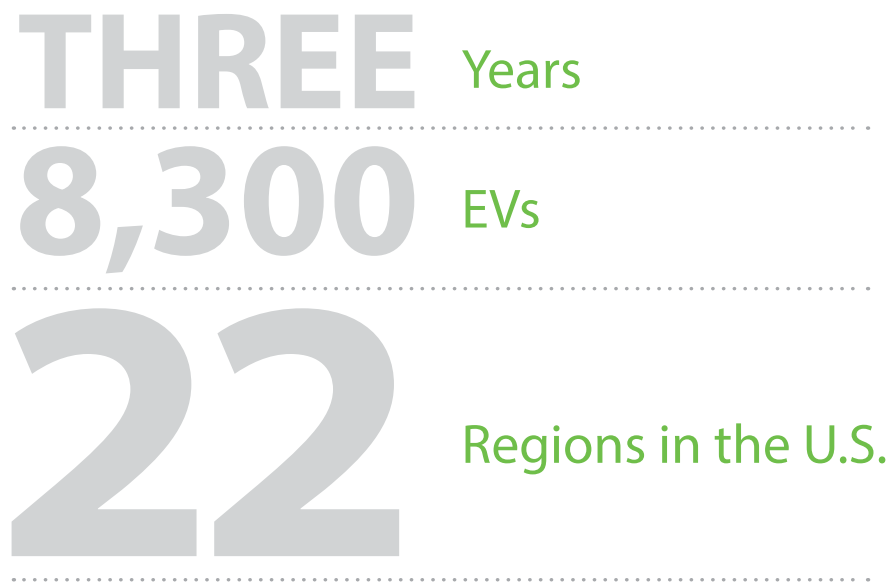

Areas where public charging infrastructure was installed and vehicles were enrolled in The EV Project and ChargePoint America.

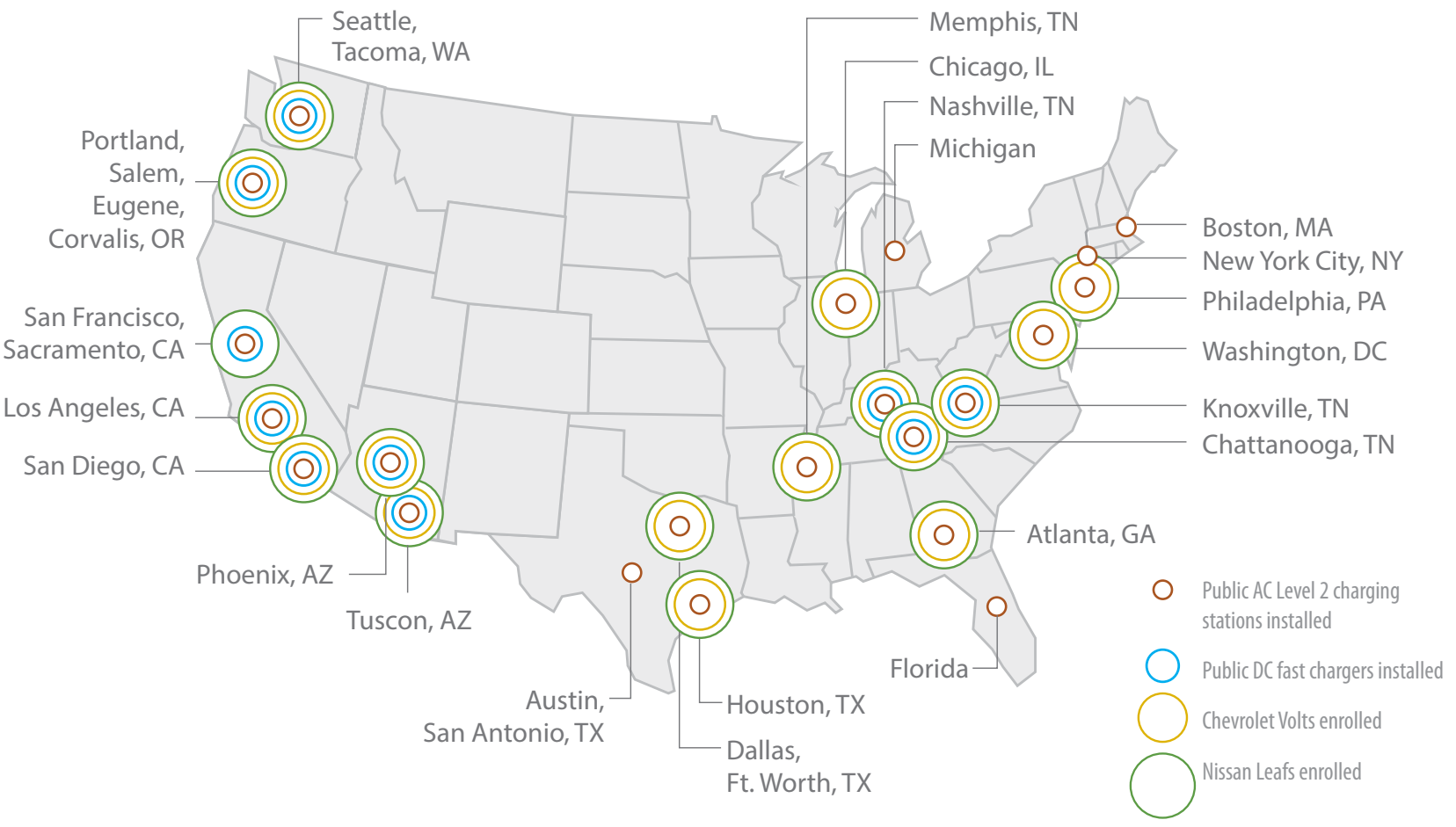




\section{What Have We Learned?}

With gas stations seemingly on every block, it would seem logical to expect that a similarly ubiquitous network of public charging stations would be needed to refuel, or rather, recharge PEVs. However, charging stations can be installed where gas stations cannot at people's homes, workplaces, and destinations where their cars spend a long time parked. The project installed AC Level 2 and DC fast charging stations in a wide variety of locations, including homes, workplaces, stores, restaurants, gas stations, and many other venues, to allow researchers to observe where PEV drivers charge. Would they plug in

\section{This study is the largest plug-in electric vehicle}

\section{infrastructure demonstration in the world.}

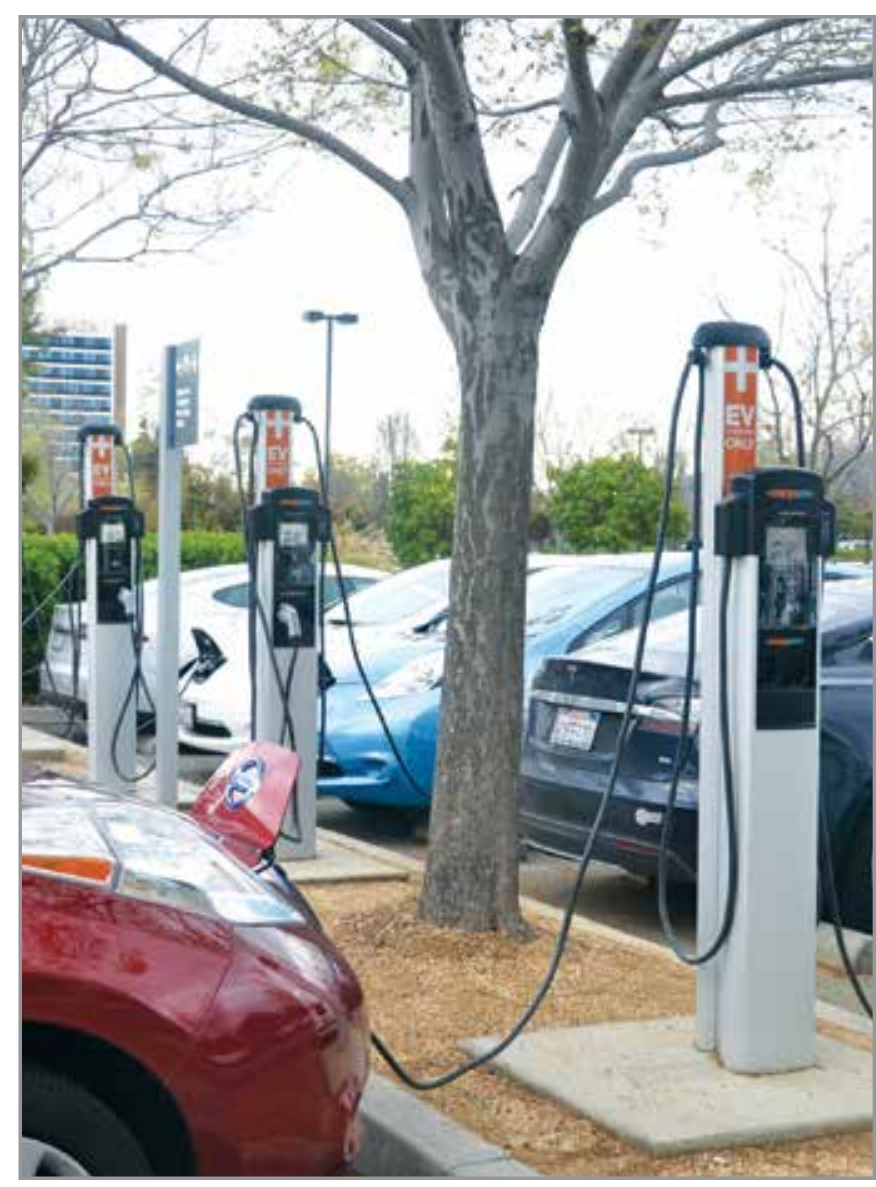

Photo courtesy of ChargePoint around town at the nearest charging station, following the pattern they followed with the gas-powered cars they grew up with, or would they adopt a new refueling paradigm and charge at the few places where they park their cars for the longest periods of time?

The answer was clear: despite the installation of extensive public charging infrastructure in most of the project areas, the majority of charging was done at home and work. About half the project participants charged at home almost exclusively. Of those who charged away from home, the vast majority favored three or fewer away-from-home charging locations, and one or more of these locations was at work for some drivers.

This is not to say that public charging stations are not necessary or desirable. Many DC fast chargers (all of which were accessible to the public) experienced heavy use to support both in-town and inter-city driving. Also, a relatively small number of public AC Level 2 public charging sites saw consistently high use. This begs the question: what is it about the small number of highly used charging sites that led to their popularity?

There was some correlation between public charging location characteristics and utilization. Public Level 2 charging stations installed in locations where vehicles were typically parked for longer periods of time often were, in fact, among those most often used. These locations included shopping malls, airports and commuter lots, and downtown parking lots or 
garages with easy access

to a variety of venues. Also, not surprisingly, public charging station utilization was higher in regions with higher PEV sales. However, there were examples of highly utilized charging sites in almost every region and at venues that did not seem to be well-suited for charging. Conversely, there were also many charging sites in seemingly ideal

\section{To support PEV driving, charging infrastructure should be}

focused at home, workplaces, and in public "hot spots" where demand for Level 2 or DC fast charging stations is high.

locations that did not experience much use.

In the end, it is apparent that the exact factors that determine what makes a public charging station popular are predominantly community-specific. More research is needed to pinpoint these local factors. Nevertheless, to support PEV driving, the

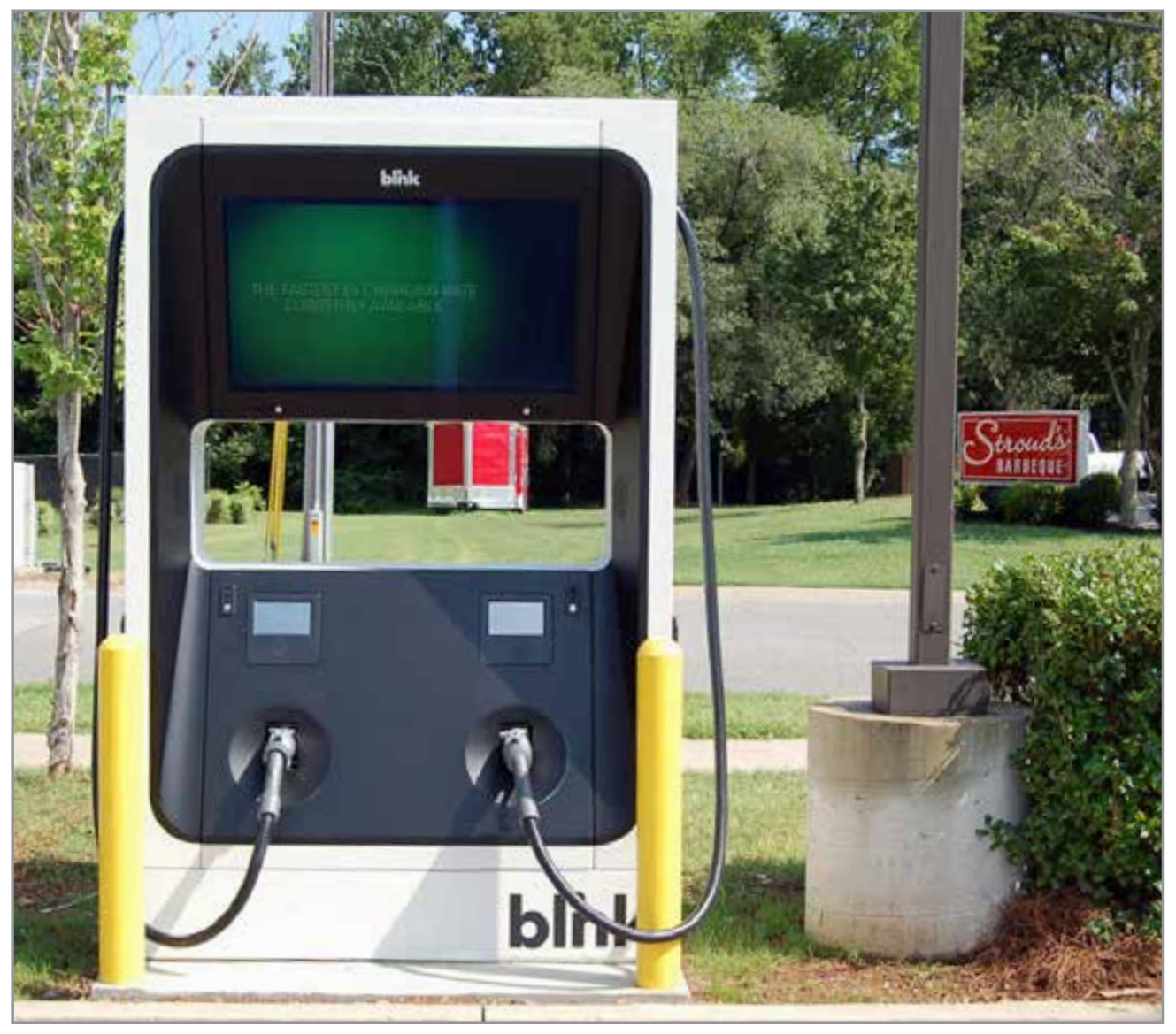


project demonstrated that charging infrastructure should be focused at home, workplaces, and in public "hot spots" where demand for Level 2 or DC fast charging stations is high. host, but when they were used, they provided a vital function to the driver.

Regardless of motivation for installing public charging infrastructure, the drivers of the Chevrolet Volt, an extended-range electric vehicle, tended to charge more frequently and to more fully deplete their vehicle's battery than drivers of the Nissan Leaf,

\section{Public and workplace charging infrastructure enabled}

drivers to increase their electric driving range, although most drivers did not charge away from home frequently.

Naturally, there are exceptions to this rule. There may be reasons for an organization to install public charging stations even if they are not used, such as to attract a certain customer demographic, communicate a "green" image, or encourage PEV adoption. The project did not study the effectiveness of charging infrastructure in meeting these goals. Additionally, DC fast chargers along travel corridors were found to effectively enable long-distance range extension for battery electric vehicles. These chargers were not typically used frequently so their value is hard to quantify from the perspective of the charger project found that public charging stations were more expensive to install than residential and workplace units. Installation costs also varied widely by region and by venue. This further emphasizes the benefit of focusing the bulk of charging infrastructure at home, work, and strategic public charging locations.

The project shed light on other facets of PEV use. It found that public and workplace charging infrastructure enabled drivers to increase their electric driving range, although most drivers did not charge away from home frequently. It was also discovered that a battery electric vehicle. This allowed the overall group of Volts studied to average nearly as many electric vehicle (EV) mode miles traveled as the Leafs in the project. Finally, based on observed charging patterns, the project found that there are opportunities to use pricing structures and other policies to manage demand for PEV charging, both in terms of charging station throughput at charging hot spots and electricity demand on the electric grid.
The next section of this report provides the basis for these conclusions by summarizing what we have learned about...

- PEV driving patterns and charging preferences

- Away-from-home charging for range extension

- Workplace charging

- Public charging station use

- Charging at home

- Charging infrastructure installation costs.

The final section of this report provides examples of how the findings of this project have helped organizations promote or prepare for PEV adoption. 


\section{What have we learned about PEV driving patterns and charging preferences?}

By focusing on data

collected in 2012 and

2013 from over 4,000 Leafs

and 1,800 Volts across the

United States, the project

provided insights into how

PEV early adopters drove

and charged their vehicles.
Volt drivers averaged only

$6 \%$ fewer EV miles per year

than Leaf drivers, despite

having less than half as

much battery energy stor-

age capacity. There were

two reasons for this. First,

Volt drivers tended to fully vehicles like the Leaf and range-extended electric vehicles like the Volt, which has an internal combustion engine that allows the vehicle to continue driving after the battery

\section{Volt drivers averaged only $6 \%$ fewer EV miles per year than}

\section{Leaf drivers, despite having less than half as much battery}

\section{energy storage capacity.}

Volt drivers averaged slightly more miles traveled annually than the 2013 national average, while the Leafs studied were driven noticeably less than the national average (see Table 1). deplete their batteries prior to recharging, whereas Leaf drivers favored recharging with significant charge left in their batteries. This is an expected difference between pure electric

Table 1

\begin{tabular}{lccc}
\hline & Leaf & Volt & $\begin{array}{r}\text { National } \\
\text { Average' }\end{array}$ \\
\hline $\begin{array}{l}\text { Average annual vehicle } \\
\text { miles traveled }\end{array}$ & 9,697 & 12,238 & 11,346 \\
\hline $\begin{array}{l}\text { Average annual electric } \\
\text { vehicle miles traveled }\end{array}$ & 9,697 & 9,112 & - \\
\hline $\begin{array}{l}\text { 'Office of Highway Policy Information, Federal Highway Administration, "Highway } \\
\text { Statistics 2013-Table VM-1," January, 2015, www.fhwa.dot.gov/policyinformation/ } \\
\text { statistics/2013/vm 1.cfm }\end{array}$ & & \\
\hline
\end{tabular}

is depleted. Second, Volt drivers plugged in more often than Leaf drivers. Volts were charged an average of 1.5 times on each day the vehicle was driven, whereas Leafs were charged 1.1 times per day driven, on average. Much of the difference between Leaf and Volt charging frequency is attributed to the fact that Volts were charged more often during the day at home. 
Average driving distance and charging frequency were consistent over time as the number of vehicles reporting data increased, with only slight seasonal variation. Figure 2 shows seasonal variation in average monthly distance traveled for the last 15 months of the project. Charging frequency (not shown) followed the same up-and-down trend.

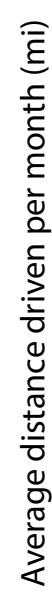

\section{Volt average monthly VMT}

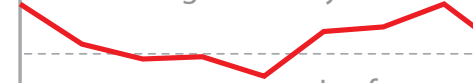

Leaf average monthly eVMT

800

60

400

200

0

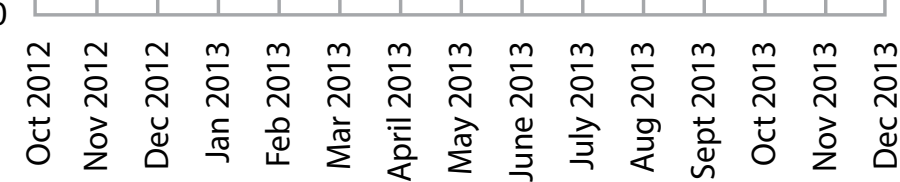

Figure 2.

Average monthly vehicle miles traveled varied seasonally but was otherwise consistent over time.
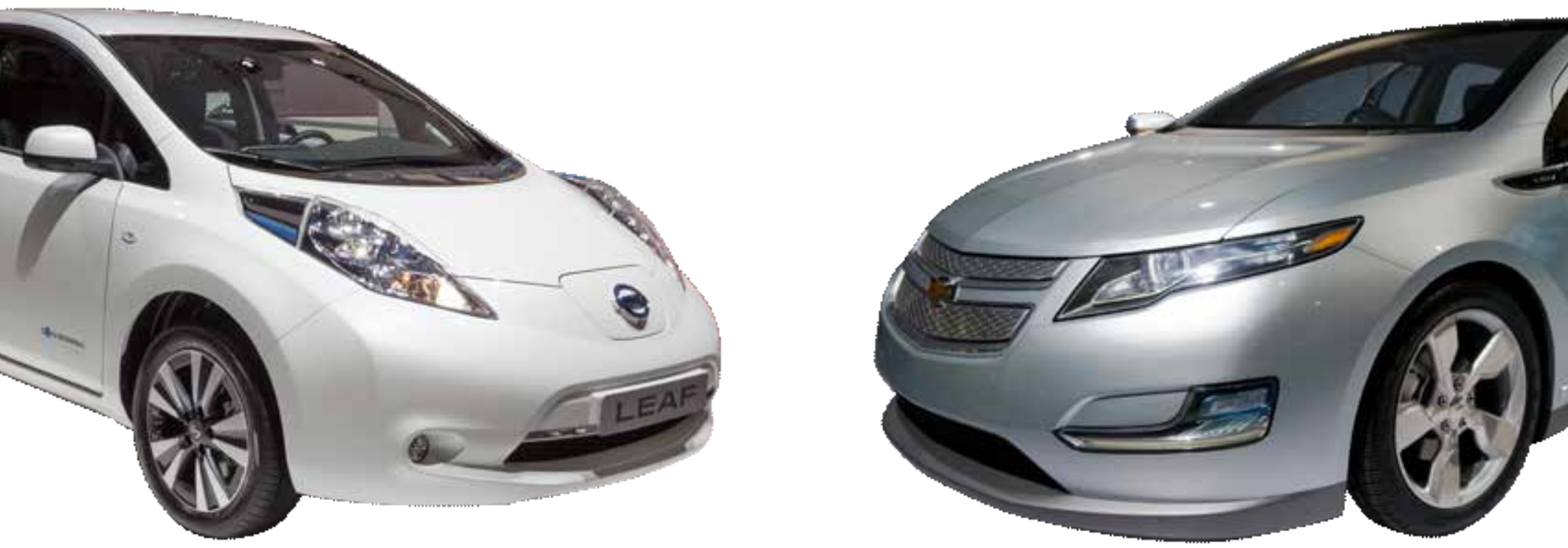
Preference for charging frequency and location Overall, Leaf and Volt drivers performed most of their charging at home (see Figure 3). Nearly all overnight charging was at home. Daytime charging was split between home and other locations, including work.
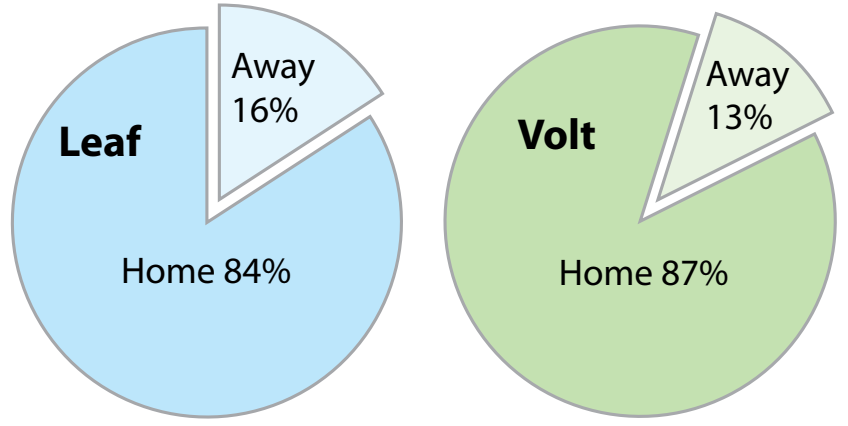

Over the weekend, daytime charging preference for both Leafs and Volts shifted slightly from away-fromhome locations to at home. Overnight charging patterns remained the same on weekdays versus weekend days, with both groups of vehicles averaging a charge nearly every night.

Drivers of $5 \%$ of Volts and $13 \%$ of Leafs only ever charged at home, and about half the drivers charged away from home less than $5 \%$ of the time. Of the drivers that charged away from home, some

Figure 3.

Leaf and Volt drivers performed most

of their charging at home.

spread their charging across many locations, but most had just a few favorite places to charge outside of home (see Figure 4). Many drivers performed a vast majority of their away-fromhome charging at only one location. Much of this can be attributed to workplace charging.
Figure 4.

$92 \%$ of Volt drivers and $77 \%$ of Leaf drivers did most (at least $80 \%)$ of their away-from-home charging at three or fewer locations. 


\section{Preference for charging equipment}

Both the Leaf and the Volt come with AC Level 1 charging cords. They are also compatible with $\mathrm{AC}$ Level 2 charging stations that use SAE J1772compliant connectors. All Leafs enrolled in the project also were capable of charging using $D C$ fast chargers with $\mathrm{CHAdeMO}$ compliant connectors. All project participants had a Level 2 charging unit installed in their homes. When charging away from home, they had the option of using any charging equipment available to them.

For the Volts collectively, about half of away-fromhome charging was done using Level 2 equipment. The other half was Level 1 charging using a dedicated charging station or a standard 120-volt outlet.

For Leafs, $8 \%$ of away-fromhome charging events was performed using DC fast chargers. The rest was AC Level 1 or AC Level 2 charging.
Each driver used a different mix of charging equipment types when charging away from home, depending on their preference and what was available. Some Volt drivers chose only Level 1 charging, which includes standard 120-volt outlets, while others chose a mix of Level 1 and Level 2 charging. Some only ever used Level 2 charging stations. For Leaf drivers charging away from home in areas where DC fast chargers were installed, some chose to only charge using Level 1 or Level 2 charging equipment, some mixed Level 1, Level 2, and DC fast charging, and a small number of drivers only charged using DC fast chargers (see Figure 5).

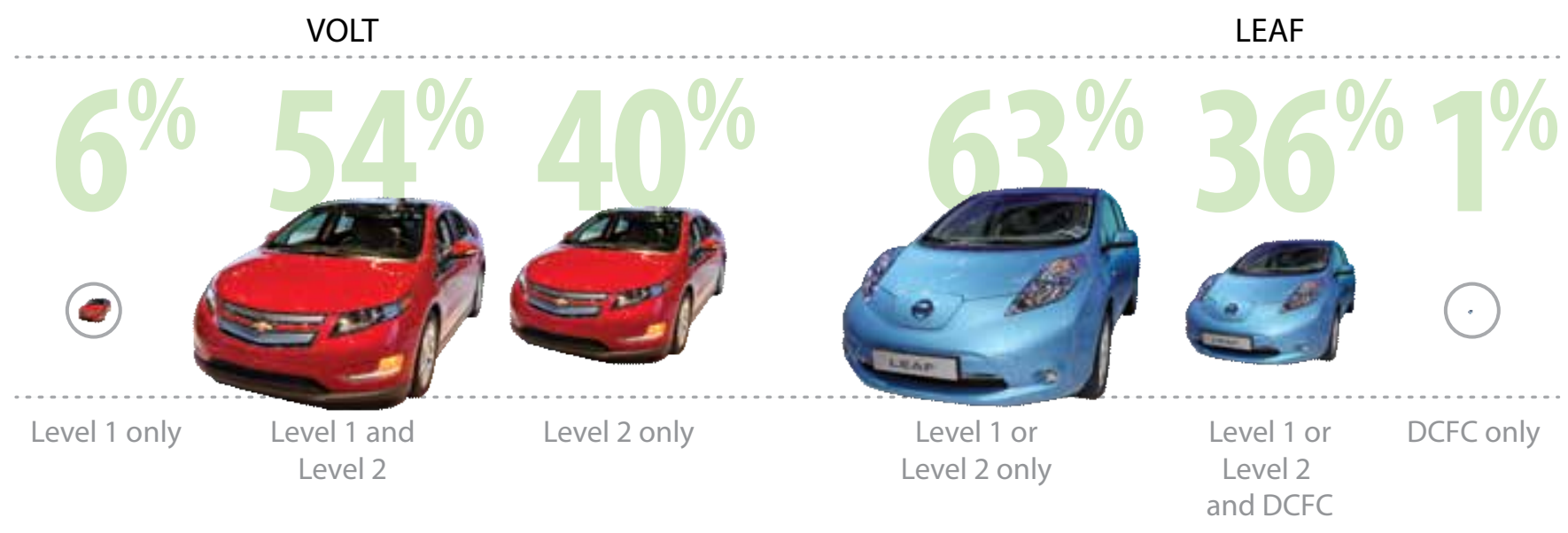

Figure 5.

How Volt and Leaf drivers

charging away from home

chose between charging equip-

ment types. 


\section{What have we learned about away-from-home charging for range extension?}

PEV drivers who plugged in away from home tended to drive more EV miles (see Table 2). In fact, drivers who frequently used away-from-home charging stations averaged $72 \%$ more daily miles on electricity alone than drivers who never charged away from home.

Table 2

\begin{tabular}{lcccc}
\hline $\begin{array}{l}\text { Tendency to charge away } \\
\text { from home: }\end{array}$ & Never & Sometimes $^{2}$ & Frequently $^{3}$ & Most of the time $^{4}$ \\
\hline $\begin{array}{l}\text { Leaf average daily driving } \\
\text { distance (mi) }\end{array}$ & 25 & 31 & 43 & 32 \\
\hline $\begin{array}{l}\text { Volt average daily driving } \\
\text { distance in EV mode (mi) }\end{array}$ & 25 & 29 & 40 & 26 \\
\hline${ }^{2}>0$ to $30 \%$ of all charging events & ${ }^{3}>30$ to $60 \%$ of all charging events & ${ }^{4}>60 \%$ of all charging events \\
\hline
\end{tabular}

However, most drivers did not charge away from home frequently (see Table 3), so the overall contribution to EV miles traveled was small.

Table 3

\section{Tendency to charge away}

\begin{tabular}{lcccc} 
from home: & Never & Sometimes $^{2}$ & Frequently $^{\mathbf{3}}$ & Most of the time $^{\mathbf{4}}$ \\
\hline Percent of Leafs & $13 \%$ & $69 \%$ & $14 \%$ & $4 \%$ \\
\hline Percent of Volts & $5 \%$ & $81 \%$ & $13 \%$ & $1 \%$ \\
\hline${ }^{2}>0$ to $30 \%$ of all charging events & ${ }^{3}>30$ to $60 \%$ of all charging events & ${ }^{4}>60 \%$ of all charging events
\end{tabular}

Figure 6.

A small fraction of vehicles were responsible for the majority of away-from-home charging.

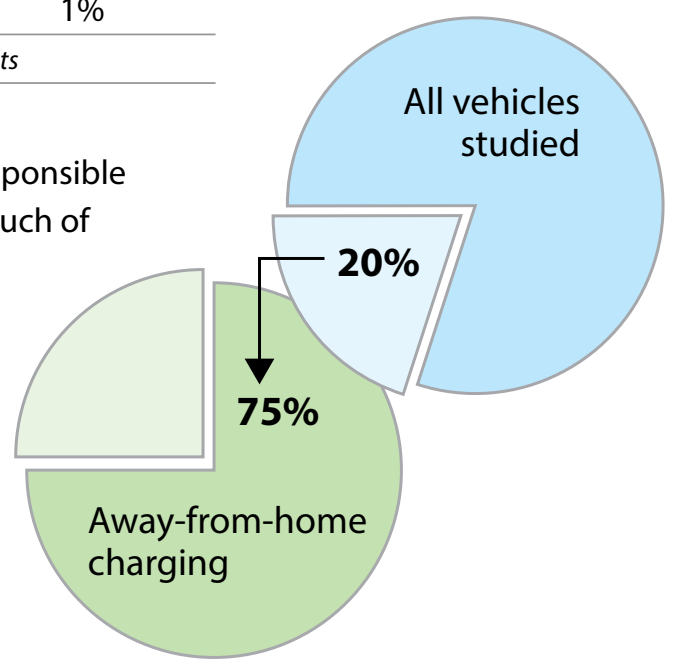

Overall, $20 \%$ of the vehicles studied were responsible for $75 \%$ of the away-from-home charging. Much of this away-from-home charging can be attributed to workplace charging (see Figure 6). 


\section{What have we learned about workplace charging?}

A subgroup of project
participants was identified
that had access to both
home and workplace
charging. Consistent with
conventional wisdom, Leaf
and Volt drivers with access
to home and work charging
performed the vast majority
of their charging at those
locations (see Figure 7).
Considering only days
when drivers went to work,
the effect is even more
pronounced. PEV drivers
performed $98 \%$ of their

charging events either at home or work and only $2 \%$ at other locations. Charging at work was free for many of these drivers, which may have been one reason why they frequently charged there.

On weekends and other days when they did not go to work, Leaf drivers averaged $8 \%$ of their charging events at locations other than home and Volt drivers averaged $11 \%$ of their charging away from home. This increased use of public charging on the weekend suggests that public charging still plays a role in these drivers' travel routines.

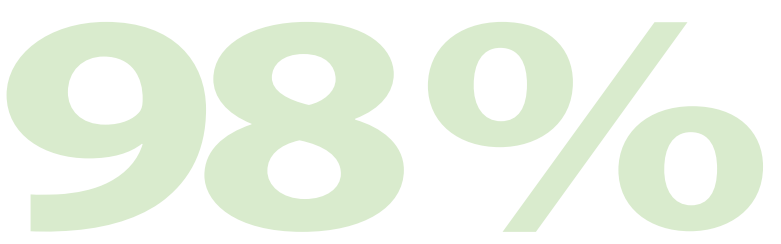

Of charging events were performed at home and work on work days.
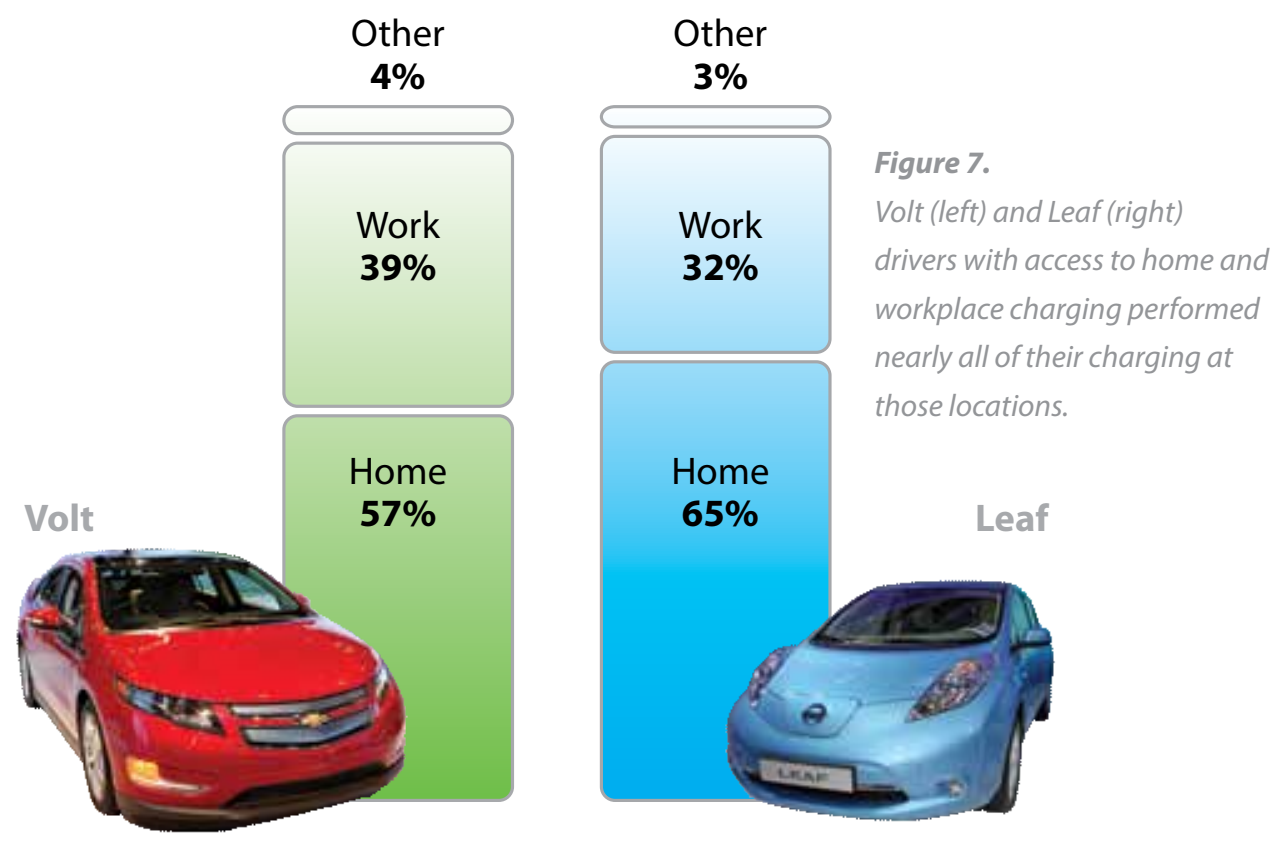


\section{Range extension from workplace charging}

Workplace charging was

found to be an effective

range extender, allowing

some Leaf owners to drive

their Leaf to work even on

days when their round-trip

commute exceeded the

vehicle's range based on

home charging alone (see

below).

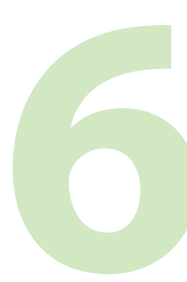

OF DRIVERS DROVE A LEAF TO WORK EVEN THOUGH THEY COULD NOT MAKE IT BACK HOME UNLESS THEY CHARGED AT WORK.

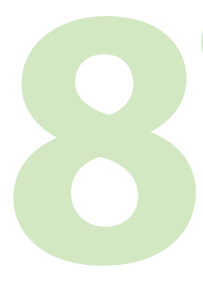

OF LEAF DRIVERS COULD COMPLETE THEIR DIRECT COMMUTE WITHOUT CHARGING AT WORK, BUT THEIR ROUTINE ON MOST DAYS REQUIRED THEM TO DRIVE ADDITIONAL DISTANCE, WHICH NECESSITATED CHARGING AT WORK IN ORDER TO MAKE IT HOME.

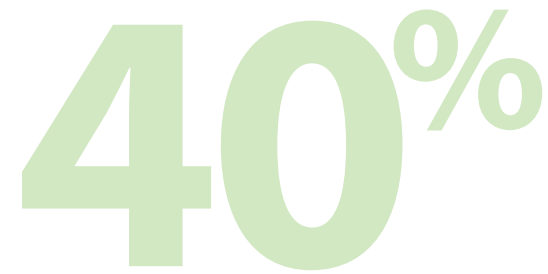

OF LEAF DRIVERS RELIED ON WORKPLACE CHARGING ON AT LEAST ONE DAY A MONTH TO COMPLETE THEIR DAILY COMMUTES.
On days when Leaf drivers had to charge at work in order to complete their daily commute, workplace charging provided an average of 15 miles of range extension required to make it home. The entire daily commute on these days, which averaged 73 miles, arguably was enabled by workplace charging.

Volt drivers saw similar electric range-extending benefits from workplace charging. On days when Volt drivers' commutes were long enough to require a charge at work in order to complete the commute on electricity alone, workplace charging provided an additional 18.5 miles of EV driving, on average. On these days, round-trip commutes averaged 62 miles, with 57 miles of EV range.

Leaf and Volt drivers with known access to workplace charging in this study averaged $23 \%$ and $26 \%$ higher annual EV miles traveled than the overall groups of vehicles in the project, respectively (see Figure 8).
Workplace charging as a substitute for home charging

About $30 \%$ of drivers only charged at work on most days. This shows that workplace charging could make PEVs viable for people without access to home charging.

\section{Management of} workplace charging PEV drivers demonstrated that they adjust their charging habits based on conditions, such as fees and rules for use. Not surprisingly, drivers were less likely to plug in at work if they had to pay to charge or if they were required to move their vehicle after charging (and that rule was enforced). PEV drivers also showed a willingness to use communication tools, such as social media, to coordinate the use of charging stations with other employees. At work sites studied, there also was a culture of common courtesy and willingness to follow local practices, such as a driver plugging in a neighboring 
car after unplugging his vehicle. In many cases, this self-management by employers led to exceptionally high charging station utilization and opportunity for a large number of employees to charge regularly.

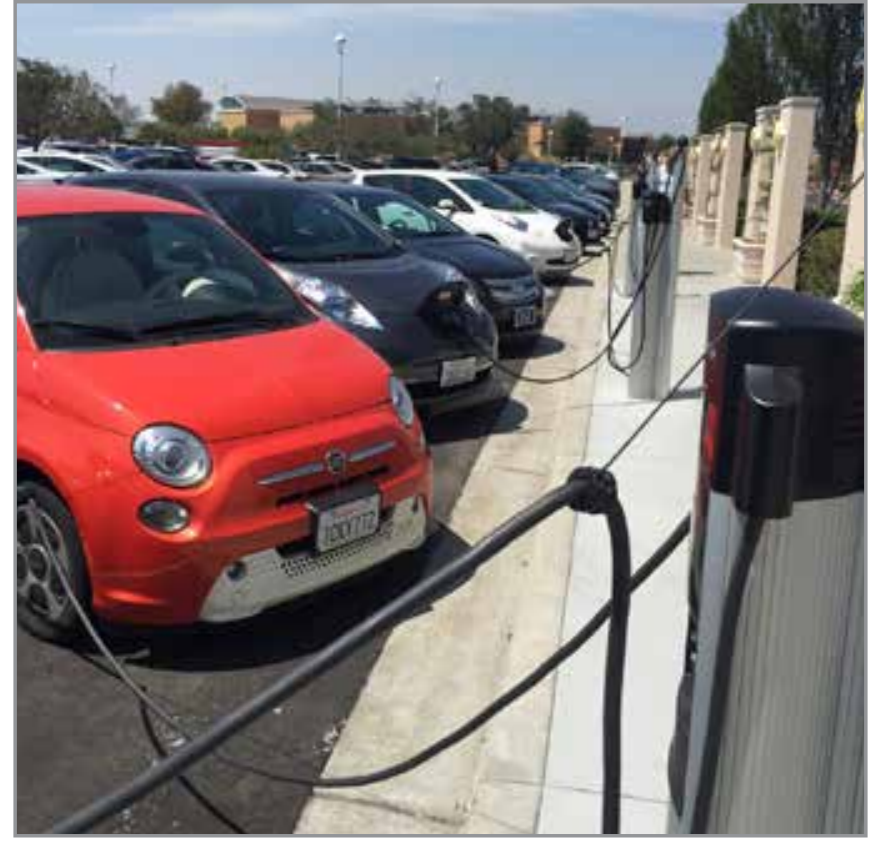

Photo courtesy of Facebook

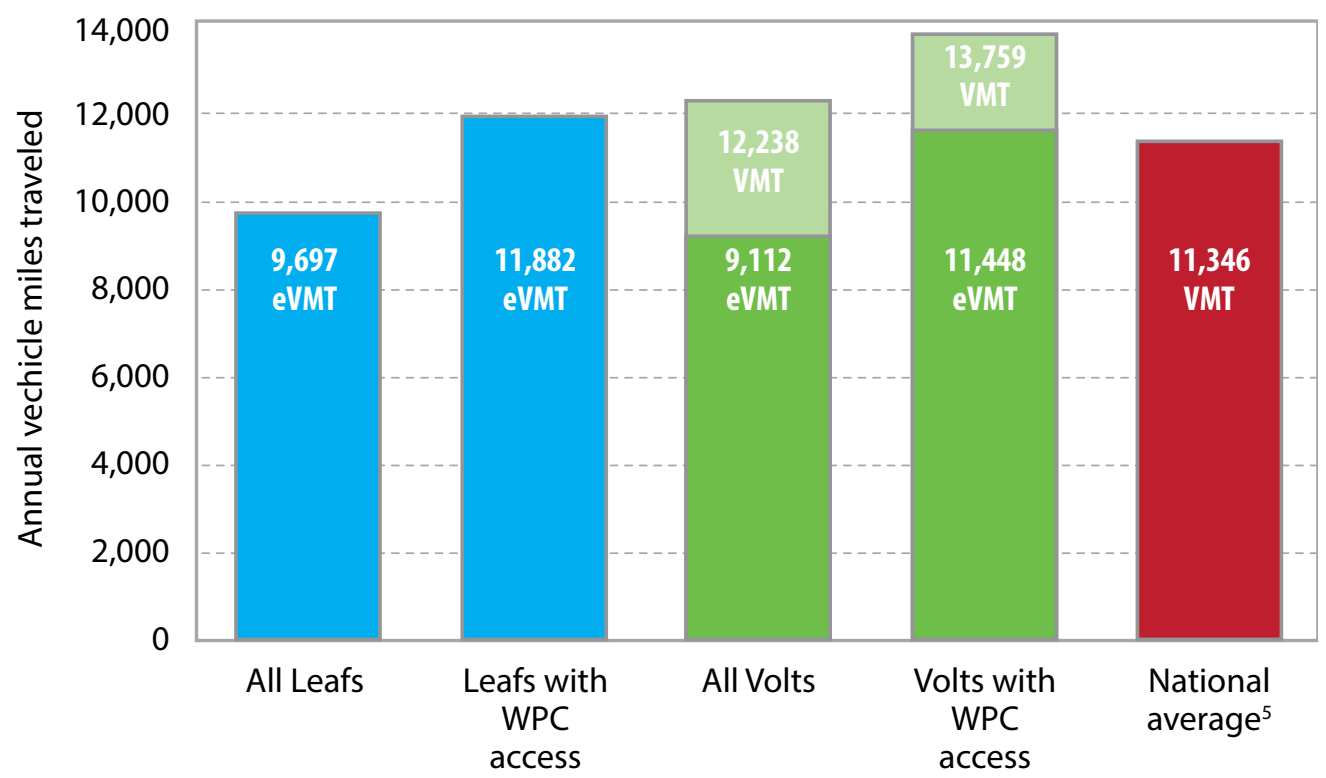

5 Office of Highway Policy Information, Federal Highway Administration, "Highway Statistics 2013-Table VM-1," January, 2015, www.fhwa.dot.gov/policyinformation/statistics/2013/vm1.cfm
Figure 8.

Volt and Leaf drivers with access to home charging and workplace charging (WPC) had considerably higher annual electric vehicle miles traveled (eVMT) than the overall project averages, and their eVMT exceeded the national average annual total vehicle miles traveled (VMT). 


\section{What have we learned about public charging station use?}

\begin{abstract}
Public Level 2 charging station usage (excluding workplace charging units) was low overall. The median charging frequency per site was 1.4 charges per week, with $75 \%$ of the 2,400 public Level 2 sites nationwide averaging four or fewer charging events per week. However, popular public Level 2 sites saw very

for an average of 8.6 hours per charge cord per day. The average time vehicles were plugged in for each individual charge event ranged from 4 to 42 hours, with a median plug-in time of 22.6 hours per event. These types of locations are prime candidates for slower, lower cost Level 1 charging equipment.
\end{abstract} high usage. Well-designed charging sites at retail stores, especially shopping malls, and parking lots and garages serving multiple venues demonstrated the potential to support from 7 to 11 charges per day.

Charging sites at venues where vehicles are parked for long periods of time, like airports, ride-share parking lots, or parking lots at public transit stations, should not be measured by the number of events per week, but rather by the time vehicles spent connected to charging stations in a day or week. In the project, these kinds of sites had vehicles connected
DC fast chargers were used much more frequently than most public Level 2 stations, with a median use frequency of 7.2 events per week, based on averaging each fast charger's use over the course of the entire project. A quarter of the fast chargers averaged over 15 events per week, and one unit averaged 70 events per week. The most highly utilized DC fast chargers tended to be located close to interstate highway exits. Interestingly, these units were used by

\section{The most highly utilized DC fast chargers tended to be located close to interstate highway exits.}

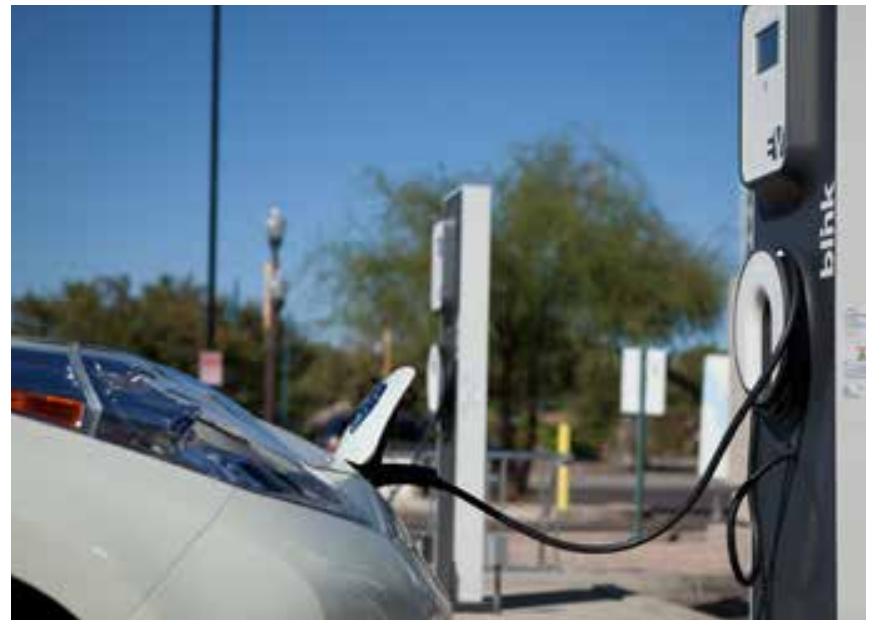

local vehicles as much or more than they were used to recharge vehicles traveling on the interstate.

Public charging station usage varied significantly by region, with average utilization rates generally tracking with regional PEV sales. However, highly utilized individual public charging sites were found in most regions, proving that public charging station utilization is dependent on local factors. More research is needed to fully characterize public charging "hot spots" and develop rules of thumb for identifying public charging locations with potential for high utilization. 


\section{How did public usage change over time?}

As mentioned, overall usage

of public Level 2 charging

stations was low, but it

slowly increased over the

course of the projects, with

usage of ChargePoint units

increasing at a faster rate

than Blink units on average

nationwide (see Figure 9).

The cost to use public Level

2 charging stations varied

from site to site. Most Blink

public units charged a fee

after September 2012. Many

ChargePoint public stations

were free through the end

of the project, but the exact

number is not known.
Blink DC fast chargers were initially free and usage increased quickly. However, usage dropped dramatically when the Blink Network implemented a usage fee in the summer of 2013. Data provided by the Blink Network after the end of the project showed that average Blink DC fast charger usage bottomed out in early 2014 and then steadily increased, reaching 2.4 charging events per day by the end of 2014 .

Prior to the onset of fees, Blink DC fast charger sessions lasted an average of
19.5 minutes. When the Blink Network began charging a per-session fee to fast charge, the average time spent charging increased by $20 \%$. Drivers presumably stayed connected longer to get their money's worth.

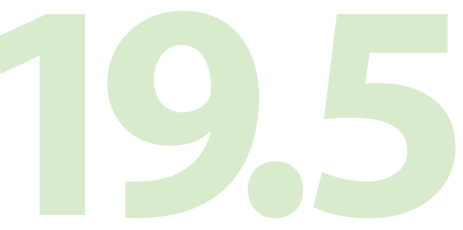

The average number of minutes in a Blink DC fast charger session prior to the onset of fees.

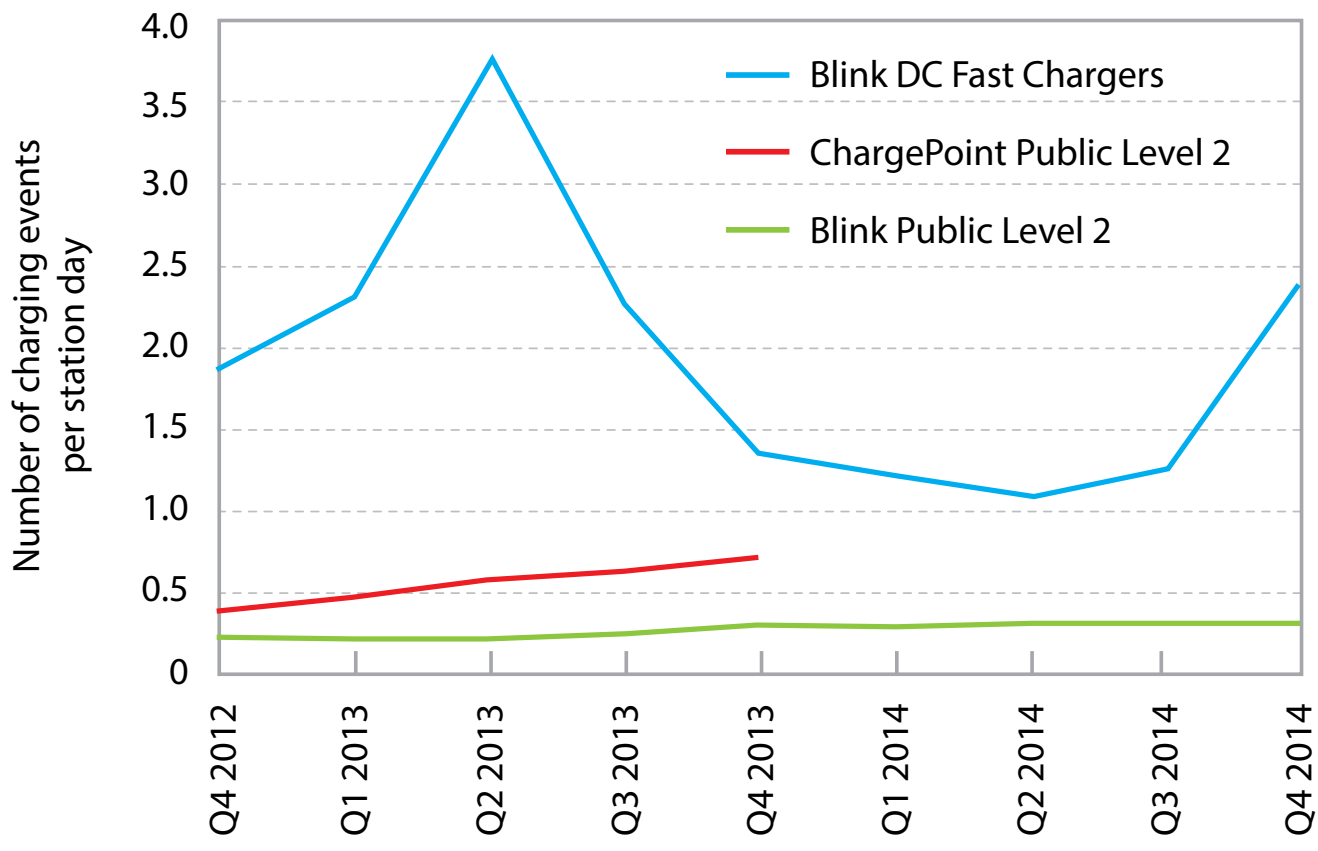

Figure 9.

Blink DC fast charger usage fell dramatically in the middle of 2013 , coinciding with the onset of fees for use, but increased again in the second half of 2014. 


\section{What have we learned about charging at home?}

\section{When do they charge?}

PEV owners have the option of delaying the start of

charging electronically, allowing them to plug in their vehicle at a convenient time but not start consuming electricity from the grid until later, such as when electricity prices are lowest. Project participants could program either their vehicle or their home charging unit to delay charging. Of those who chose to delay their charging using these tools, about half programmed their charging unit and half programmed their vehicle. Some customers chose to program their charging unit, rather than their vehicle, to avoid needing to override the vehicle's

\section{The vehicles always required less than 5 hours to fully}

\section{charge at home using the Level 2 charging units, and}

charge delay setting when they plug in away from home during the day.

Participants in the project left their vehicles plugged in at home overnight for an average of 12 hours per charge. The vehicles always required less than 5 hours to fully charge at home using the Level 2 charging units, and usually only took 1 to 3 hours to charge completely. This means that even though most vehicles were plugged in for the night by 10 p.m.,

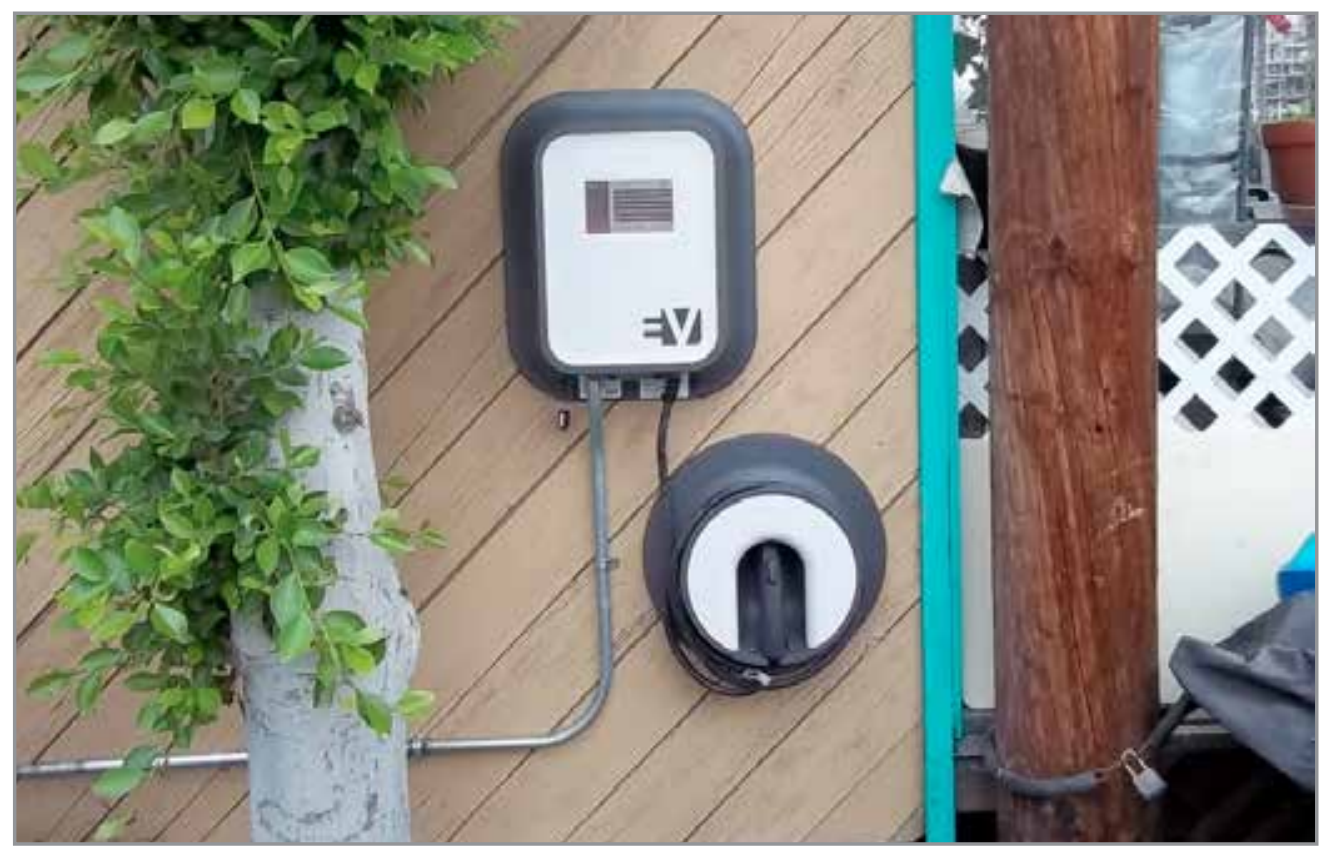


overnight charging at home typically could be delayed until the early morning hours when overall demand on the electric grid is the lowest. In fact, many electric utilities offer reduced home electricity prices during off-peak times to incentivize their customers to shift electricity consumption off peak. PEV owners in the project in areas where utilities offer cheaper rates at night showed a willingness to delay charging at home until these off-peak periods. In San Diego, where the cheapest time to charge was between midnight and 5 a.m., most PEV owners programmed their charging to start at midnight or 1 a.m. (see Figure 10).

The Volt and Leaf both offer a charge scheduling option that allows the owner to tell the vehicle what time they plan to depart on their next trip. The vehicle chooses what time to start charging, based on how empty the battery is and how much time it calculates it needs to charge. This "depart-by time" scheduling function is helpful for the electric grid, because it essentially randomizes the charge start time from household to household, thus preventing all vehicles from initiating charging at the same time, such as the start of the offpeak period.

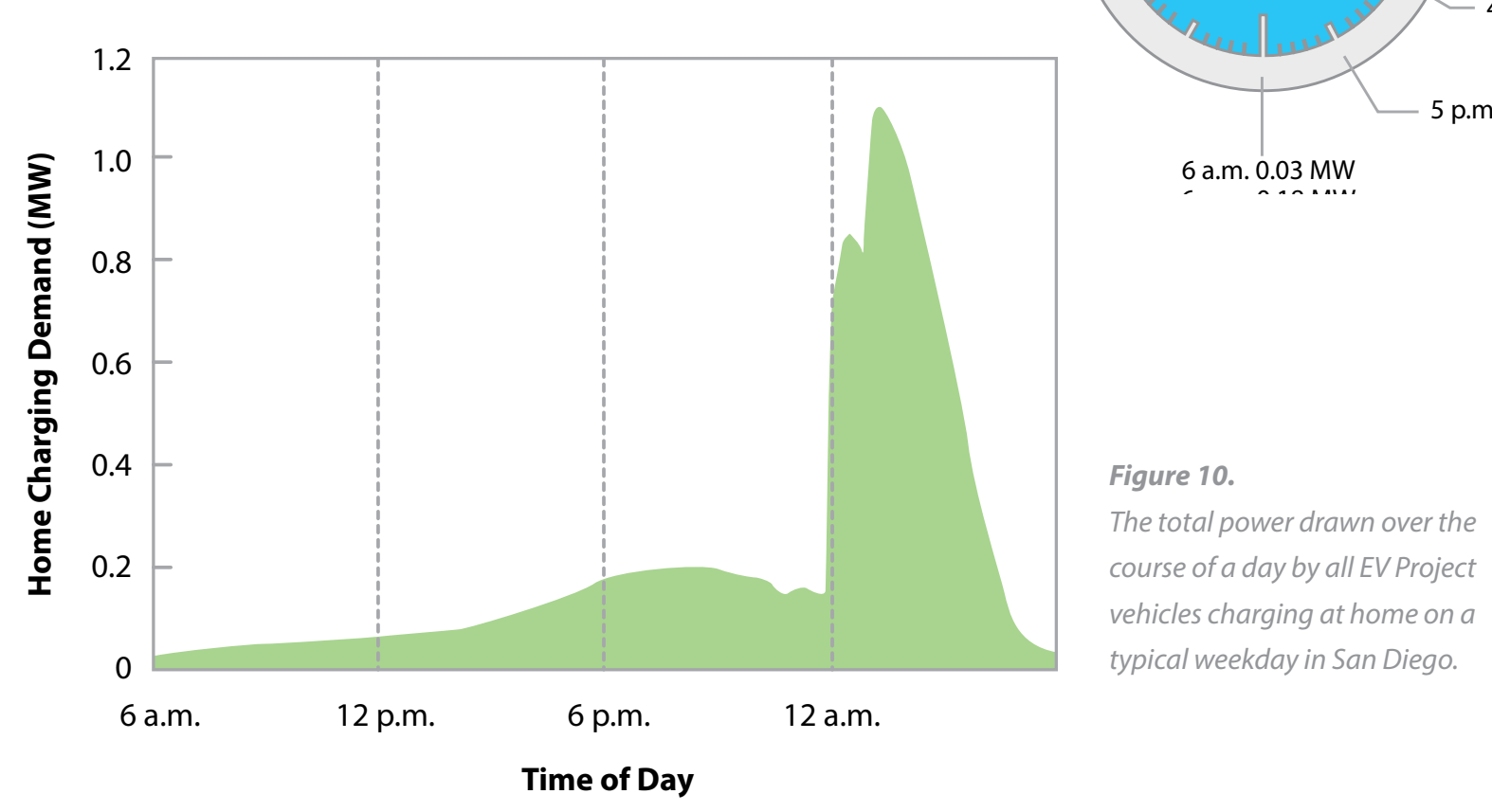




\section{What have we learned about charging station installation costs?}

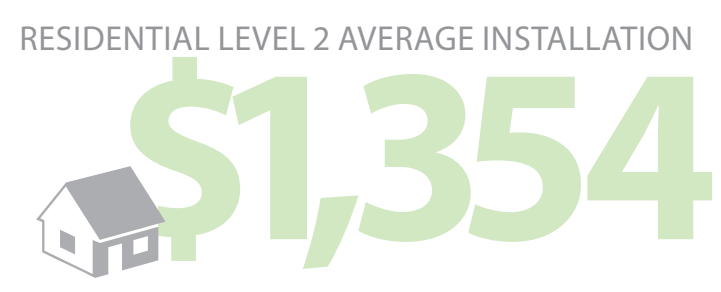

WORKPLACE LEVEL 2 AVERAGE INSTALLATION

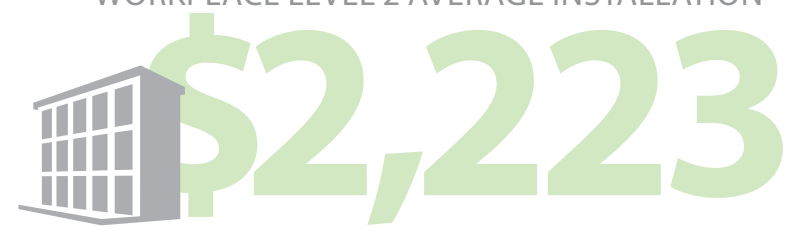

PUBLIC LEVEL 2 AVERAGE INSTALLATION

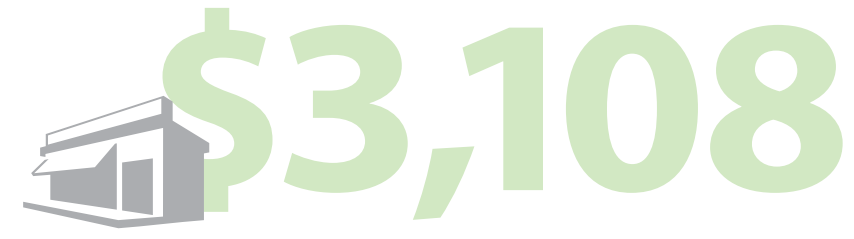

BLINK DC FAST CHARGER AVERAGE INSTALLATION

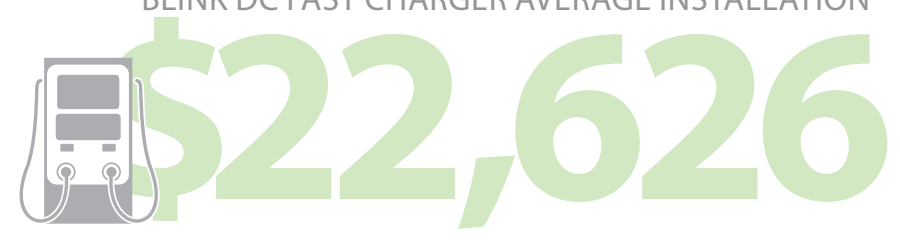

Installation cost for residential, workplace, and public charging stations was documented for the Blink stations installed in the project. Residential Level 2 unit installation cost ranged from a few hundred dollars to over $\$ 8,000$. The average residential installation cost was $\$ 1,354$. This average was driven up by expensive installations that required upgraded electrical service, which was often necessary in older homes. Cost varied regionally based on electrician labor wages and permitting fees.

The installation cost of public Level 2 charging stations ranged from $\$ 600$ to $\$ 12,660$, with an average cost of $\$ 3,108$. Cost primarily depended on the distance from the facility's electrical panel to the charging station location, and varied regionally due to labor costs.

Workplace Level 2 charging unit installations averaged $\$ 2,223$, or $28 \%$ less than the average public Level 2 unit cost. This difference was attributed to workplaces having more flexibility in choosing the locations of their charging stations and the type of equipment to be installed. However, employers that installed additional charging stations often found the second round of installations to be more expensive because the inexpensive locations had been taken already.

Blink DC fast charger installation cost in the project ranged from $\$ 8,500$ to over $\$ 50,000$, with an average cost of $\$ 22,626$. This average actually may be artificially low, because installation proposals that exceeded a spending limit were turned down. Many DC fast charger installations required the addition of electrical service to support the chargers' $60-\mathrm{kW}$ power rating and requirement for 480 -volt 3-phase power. This significantly increased the installation cost. Like with Level 2 units, costs varied regionally depending on permitting requirements and labor costs. 
Vehicle regulation

As an independent third

party, Idaho National

Laboratory performed anal-

ysis of PEV driving data from

the project and additional

data sets and presented

results to the California Air

Resources Board to support

deliberations between

the Air Resources Board

and automakers about the

redefinition of zero-emis-

sion vehicle credits. $A$

revision to this regulatory

framework applied to

cars sold in California, the

largest market in the United

States, would potentially

shift billions of research

and development dollars

at various auto companies.

The study was performed

on a data set of $158,000,000$

miles from 21,000 vehicles

operated throughout the

United States. Eight models from five automakers (Ford, GM, Nissan, Honda and Toyota) were included.

\section{Other partners and beneficiaries}

Analysis results and findings published over the course of the project have been used by a host of other organizations, including standards development committees, other auto companies and electric utilities in the United States and abroad, PEV charging equipment manufacturers, facilities management companies, PEV advocacy groups, and federal and state government agencies to inform PEV and charging infrastructure design and deployment decisions, electricity grid load forecasting, cost/benefit analyses, and a variety of other endeavors.

\section{For more information about The EV}

Project and ChargePoint America, including publications detailing additional findings and lessons learned, visit avt.inl.gov/evproject and avt.inl.gov/chargepoint.

Numerous organizations were provided with special reports or presentations to aid their research, planning or policy decisions related to electric vehicles and charging infrastructure design, promotion and environmental impact. These groups include the following:

- Argonne National Laboratory

- Arizona Public Service

- California Air Resources Board

- California Energy Commission

- Cardiff University, UK

- Center for Climate and Energy Solutions (formerly the Pew Center on Global Climate Change)

- City of Chattanooga, TN

- City of Knoxville, TN

- Clinton Foundation Clinton Climate Initiative

- Colorado State University

- Columbia Hospitality

- Commonwealth Edison Company

- Delaware Valley Regional Planning Commission

- Electric Drive Transportation Association

- Energy \& Environmental Resources Group, LLC

- Eugene Water \& Electric Board

- Harvard University

- International Energy Agency

- Georgia Power

- Green Mountain College

- London Hydro, Inc.

- Los Angeles Department of Water \& Power

- Memphis Light Gas \& Water

- Middle Tennessee Electric Membership Corporation

- Nashville Electric Service
- National Academy of Sciences Committee on Overcoming Barriers to EV Adoption

- National Renewable Energy Laboratory

- Oak Ridge National Laboratory

- Oncor Electric Delivery

- Pacific Gas \& Electric

- Pacificorp

- PECO Energy Company

- Portland General Electric

- Public Utility District No. 1 of Snohomish County

- Puget Sound Energy

- Sacramento Municipal Utility District

- Salem Electric

- Salt River Project

- San Diego Gas \& Electric

- Seattle City Light

- Seattle University

- Southern Company

- Tucson Electric Power

- Union of Concerned Scientists

- University of California - Davis Institute for Transportation Studies

- University of Central Florida

- University of Georgia

- University of Texas Austin

- Vermont Energy Investment Corporation

- Wall Street Journal

- Washington State Department of Transportation 
For more information about INL, visit www.inl.gov.

INL/EXT-15-35584 